\title{
DENSITÉ DE POPULATION ET INTENSITÉ D'UTILISATION DU SOL AU LIBÉRIA
}

Parmi les études consacrées aux problèmes des relations entre la densité de population et les différents traits de l'agriculture, de nombreuses concernent l'intensité d'utilisation du sol, notamment celle observée en Afrique Noire (Skotnicki 1986).

Le cas du Libéria peut être analysé ${ }^{1}$ grâce aux documents cartographiques relativement bons, bien qu'ils ne permettent d'étudier que la situation dans les années cinquante et soixante-dix: il s'agit des cartes de la répartition de la population (par points) et de l'utilisation du sol, publiées en 1983 (Republic of Libéria. Planning and Development Atlas 1983). Utilisant ces cartes, nous avons pu dresser des cartogrammes, à l'aide d'une grille de 1020 carrés de $10 \times 10 \mathrm{~km}$, dans lesquels nous avons noté les taux dominants, concernant les deux phénomènes. Pour la population, les paliers de 1 à 5 , correspondent aux densités de 0 à 1 , de 1 à 5 , de 5 à 10 , de 10 à 20 , et de plus de $20 \mathrm{hab} . / \mathrm{km}^{2}$. Pour l'utilisation du sol, ils représentent respectivement les catégories dominantes suivantes, prises en compte dans les cartes libériennes: "forêt", "culture sur brûlis extensive". "culture sur brûlis intensive", "plantations", "villes et mines".

La répartition des densités en 1953 (Fig. 1) semble être liée aux types d'utilisation du sol (Fig. 2). $69 \%$ de carrés correspondent aux rangs 1 ou 2 et sont situés surtout au Sud-Est (à l'exception de la région méridionale près de la frontière ivoirienne) et à l'Ouest, le long de la frontière avec le Sierra Leone. Sur la carte d'utilisation du sol, ces terrains sont classés "forêt", avec très peu d'activité agricole. Le centre du pays, depuis la côte (surtout les environs de Monrovia) jusqu'au Nord (une zone de carrés correspondant aux rangs 3,4 ou 5 le long de la frontière avec la Guinée) est le plus densément peuplé - ainsi que les confins au Sud, près de la Côte d'Ivoire. Là, on retrouve aussi les rangs d'utilisation du sol les plus élevés.

\footnotetext{
1 Texte issu d'une thèse de maitrise préparée sous la direction de M. Skotnicki dans le cadre d'une série d'études sur les relations entre la densité de population et le caractère de l'agriculture dans les pays en voie de développement.
} 


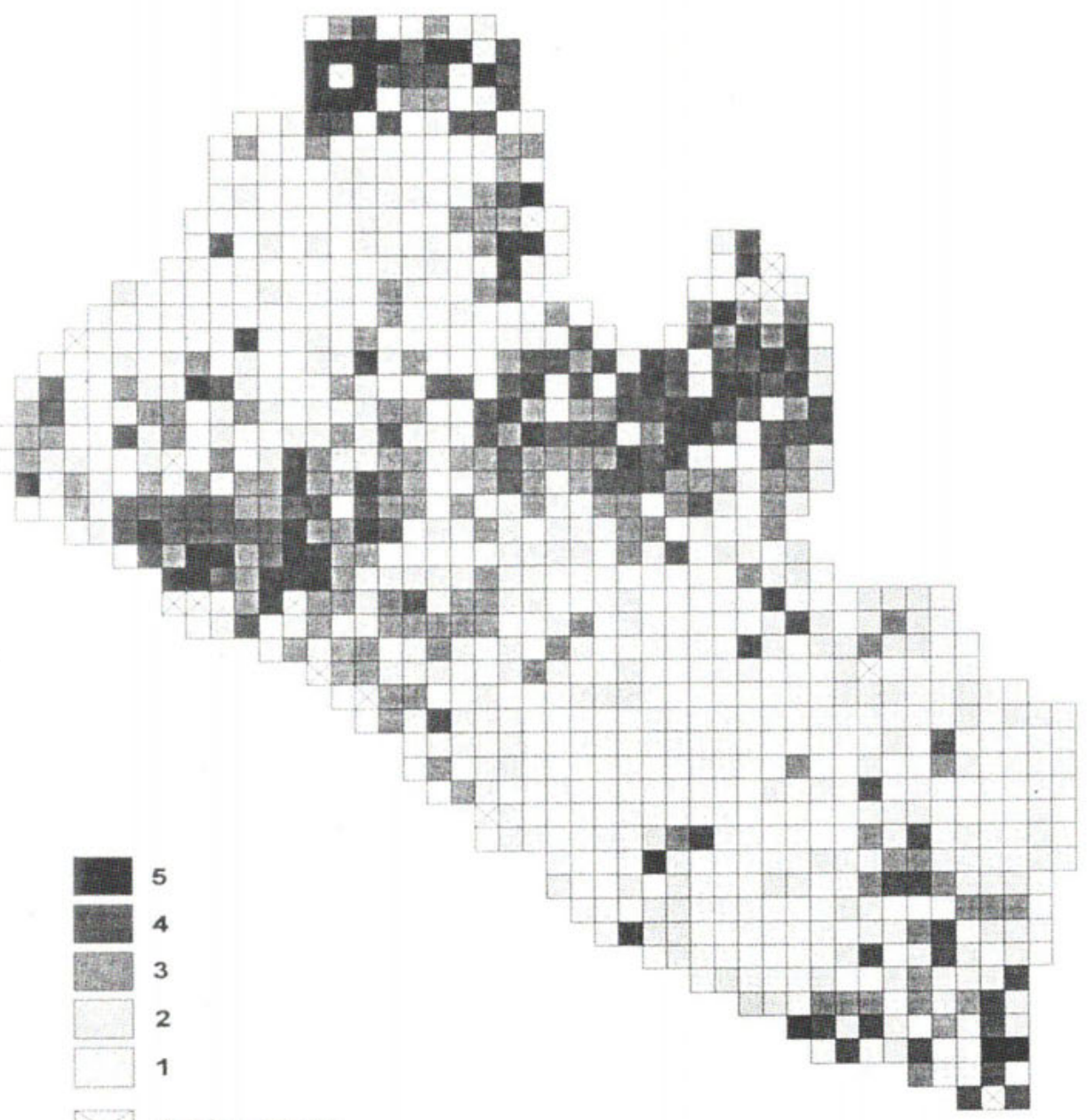

donnèes absentes

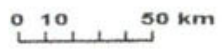

Fig. 1. Densité de population en 1953:

1 - de 0 à $1 ; 2-$ de 1 à $5 ; 3-$ de 5 à $10 ; 4-$ de 10 à $20 ; 5$ - plus de 20 hab./. $\mathrm{km}^{2}$. 


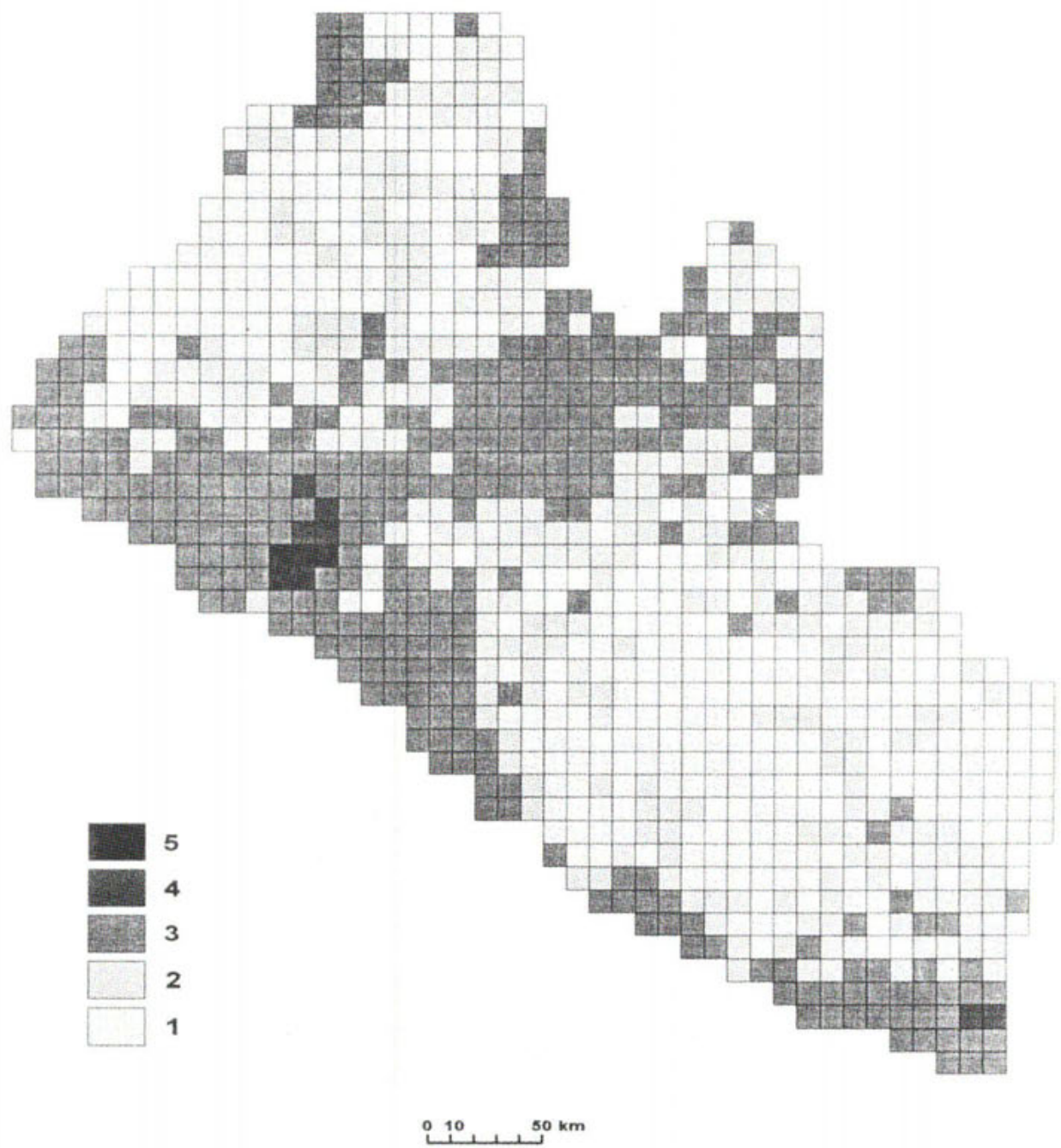

Fig. 2. Utilisation du sol en 1953 (prédominance des catégories):

1 - forêt; 2 - culture sur bralis extensive; 3 - culture sur brulis intensive;

4 - plantations; 5 - villes et mines. 
La carte représentant cette relation (Fig. 3) a été obtenue en comparant les rangs des carrés de la Fig. 1 et la Fig. 2 (soustraction: valeur du rang de la densité de population - valeur du rang de l'utilisation du sol). Les différences pouvaient s'élever de -4 à +4 . La différence $0(504$ carrés, $50,1 \%)$ indiquait la corrélation entre ces deux phénomènes; bien entendu, et c'est la faute de la méthode, cette différence ne pouvait jamais être obtenue partout, car dans chaque palier le nombre des carrés relatifs à la population n'était pas le même que celui des carrés relatifs à l'utilisation du sol. L'augmentation des différences indiquait, selon ce procédé, que l'influence d'un de ces phénomènes sur l'autre diminuait. Les valeurs positives signifieraient que la densité de la population est supérieure par rapport à l'intensité d'utilisation du sol (268 carrés, $26,7 \%$ ), les valeurs négatives - la situation inverse (233 carrés, 23,2 \%). Les carrés avec les différences faibles $(-1$ ou +1$)$ représentaient $35,7 \%$ de l'ensemble. Avec ceux où la différence était de 0 , ils constituaient donc $85,8 \%$.

Les mêmes comparaisons ont été effectuées pour les années soixante-dix. La répartition des densités de population en 1974 (Fig. 4) ressemblait à celle de 1953. Le nombre des carrés correspondant aux rangs les plus élevés a bien sûr augmenté, surtout au Sud et au Centre du pays. D'après la carte d'utilisation du sol en 1979 (Fig. 5), trois zones se distinguent: celles de la faible intensité au Nord-Ouest et au Sud-Est (rangs 1 et 2) et celle d'intensité plus élevée (rang au moins 3), située au Centre et sur la côte Ouest.

Sur la carte des relations (Fig. 6), 41,9\% des carrés correspondent à la différence 0 , dans $40,3 \%$ elle est positive (surtout au Nord et dans le Sud-Ouest), dans $17,8 \%$ - négative (au Centre). En gros, la relation entre la densité de population et l'utilisation du sol est toujours visible, bien que moins manifeste que dans les années cinquante, car les carrés avec les différences faibles $(-1$ ou +1$)$ représentent $35,8 \%$, et avec ceux où la différence est de 0 - seulement $77,7 \%$ de l'ensemble.

Il est enfin intéressant de voir si, pendant cette période de vingt ans, les changements dans les densités de population correspondaient aux changements dan. l'utilisation du sol. La carte (Fig. 7) indique les carrés où la densité a augmenté plus que l'intensité d'utilisation du sol (valeurs positives), et ceux où la situation était inverse (valeurs négatives). Dans presque la moitié de carrés $(49,3 \%)$ ces changements étaient sensiblement les mêmes, dans $39,1 \%$ de cas les différences étaient faibles $(-1$ ou +1$)$. En somme, les tendances conformes à l'idée de relation entre la densité de population et l'utilisation du sol étaient manifestes dans $88,4 \%$ du pays.

Cette relation était, d'après la lecture des cartes, moins visible dans les années soixante-dix que dans les années cinquante. Étant donné un fort accroissement démographique, les cas où les densités de population étaient supérieures par rapport à l'utilisation du sol, devenaient plus nombreux.

Voici donc les tendances observées jusqu'aux années soixante-dix. Il serait intéressant de voir si elles se sont par la suite confirmées. 


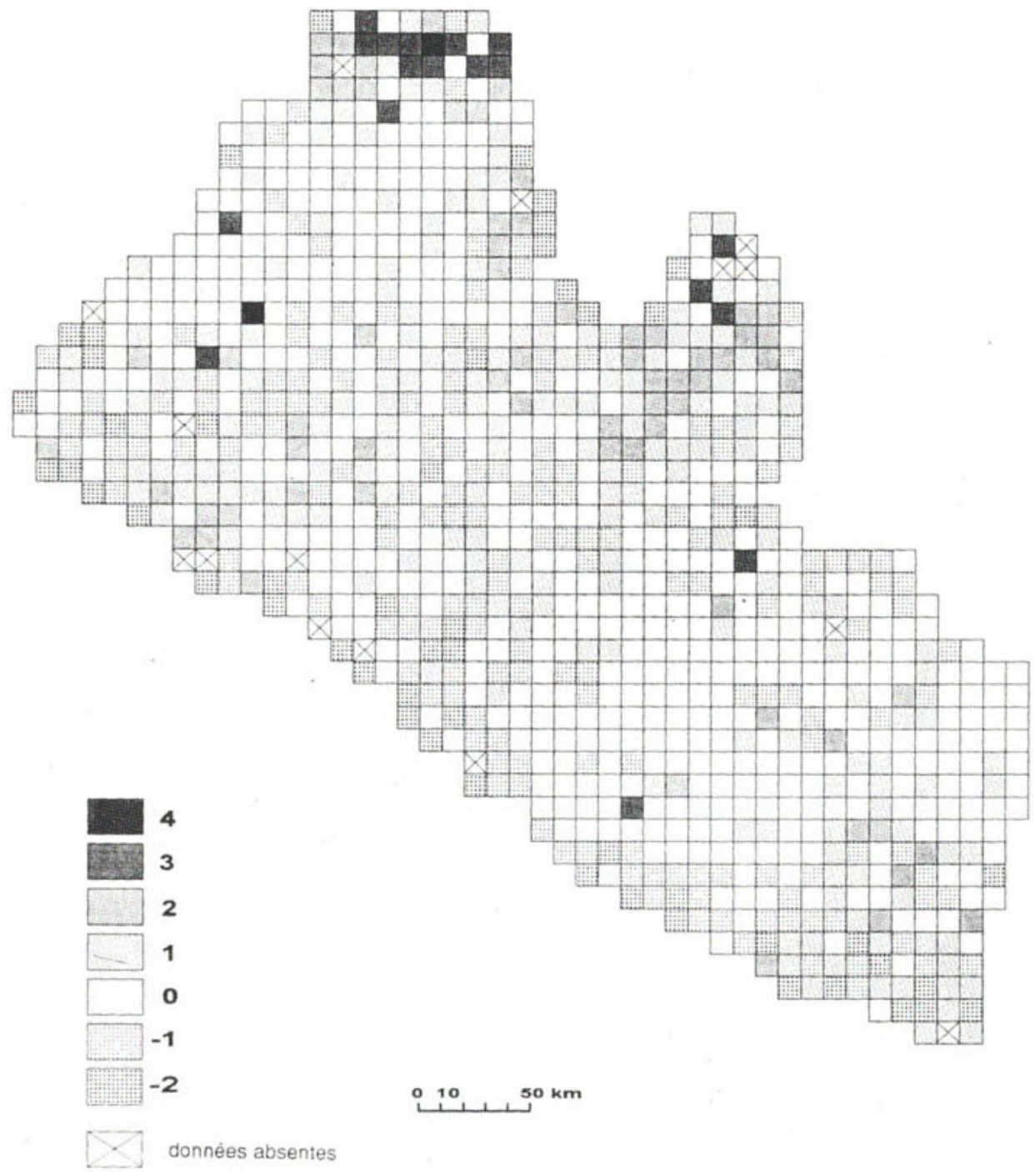

Fig. 3. Relations entre la densité de population et les catégories d'utilisation du sol en 1953 (différences entre les rangs respectifs). 


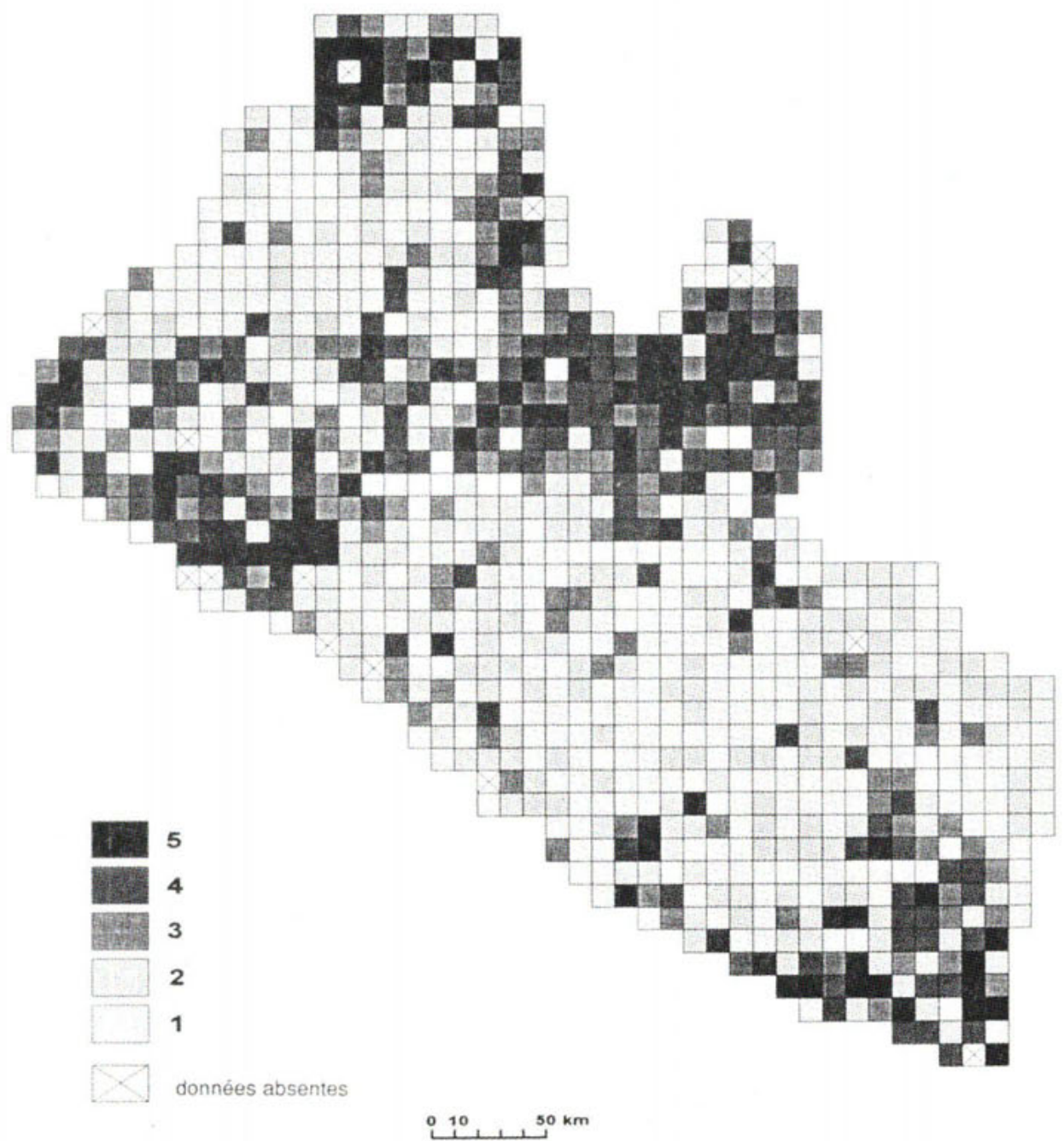

Fig. 4. Densité de population en 1974: 1 - de 0 à $1 ; 2-$ de 1 à $5,3-$ de 5 à 10 ; 4 - de 10 à $20 ; 5$ - plus de $20 \mathrm{hab} . / \mathrm{km}^{2}$. 


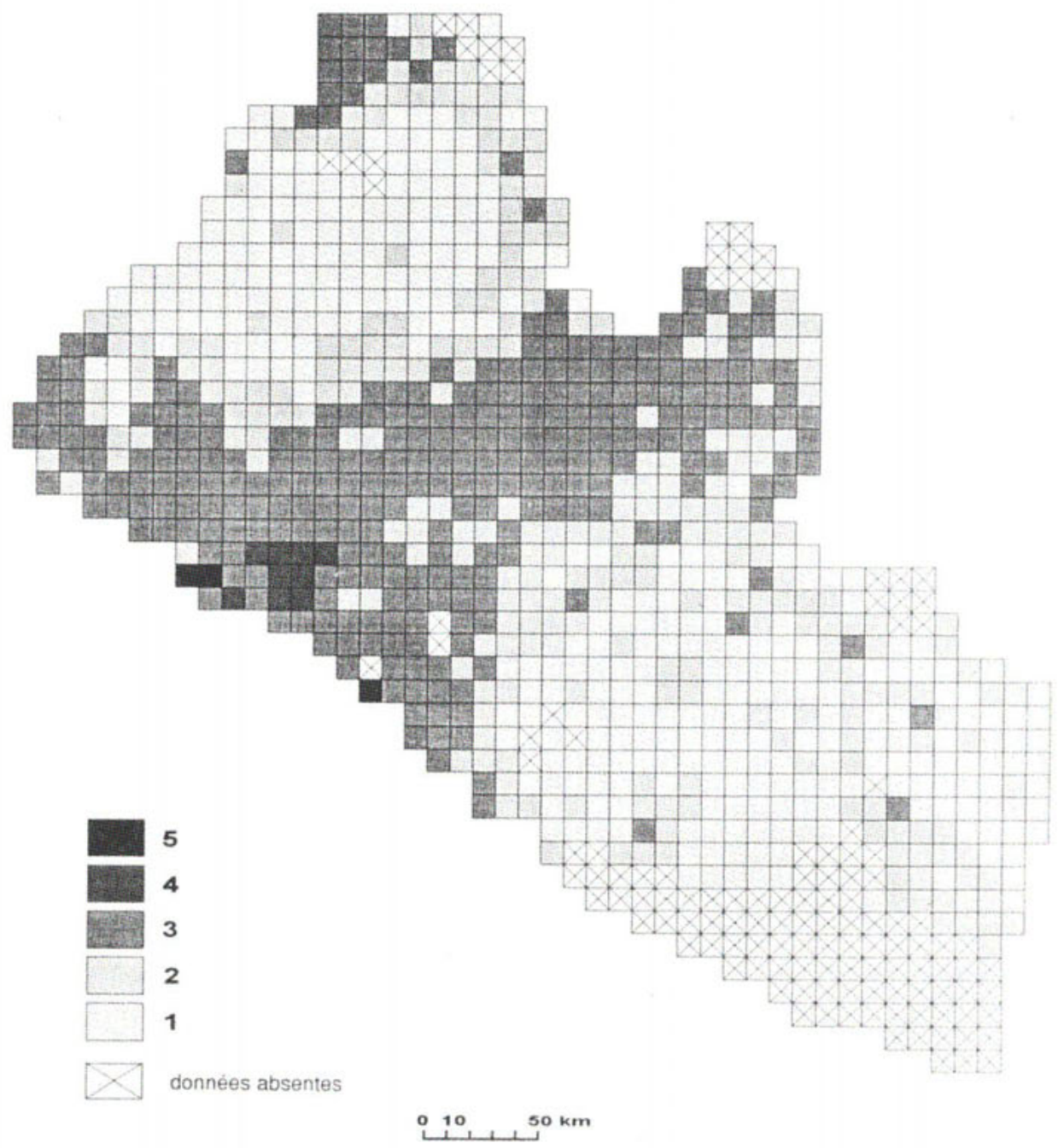

Fig. 5. Utilisation du sol en 1979 (prédominance des catégories): 1 - forêt; 2 - culture sur brulis extensive; 3 - culture sur bralis intensive; 4 - plantations; 5 - villes et mines. 


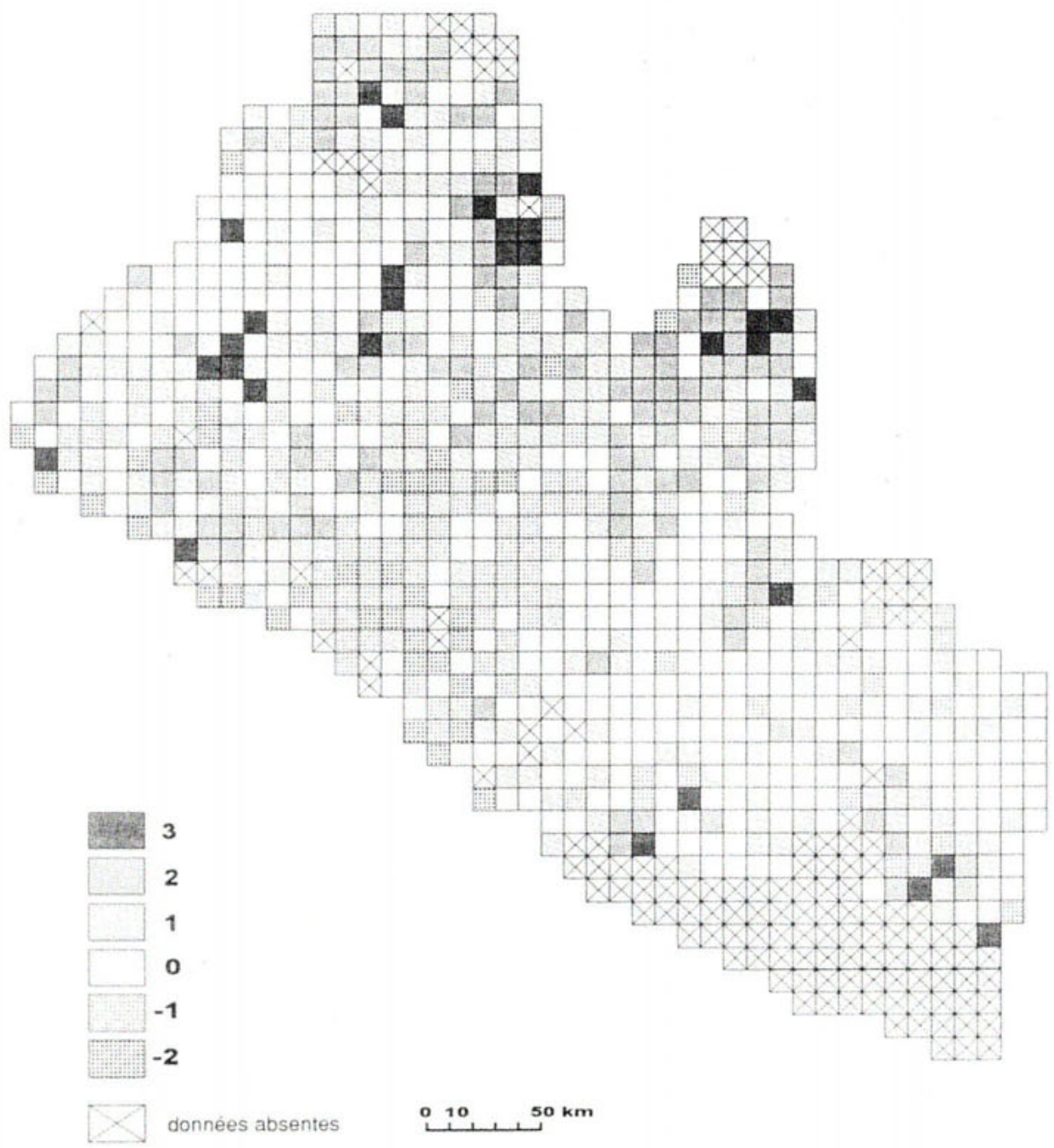

Fig. 6. Relations entre la densité de population et les catégories d'utilisation du sol dans les années soixante-dix (différences entre les rangs respectifs). 


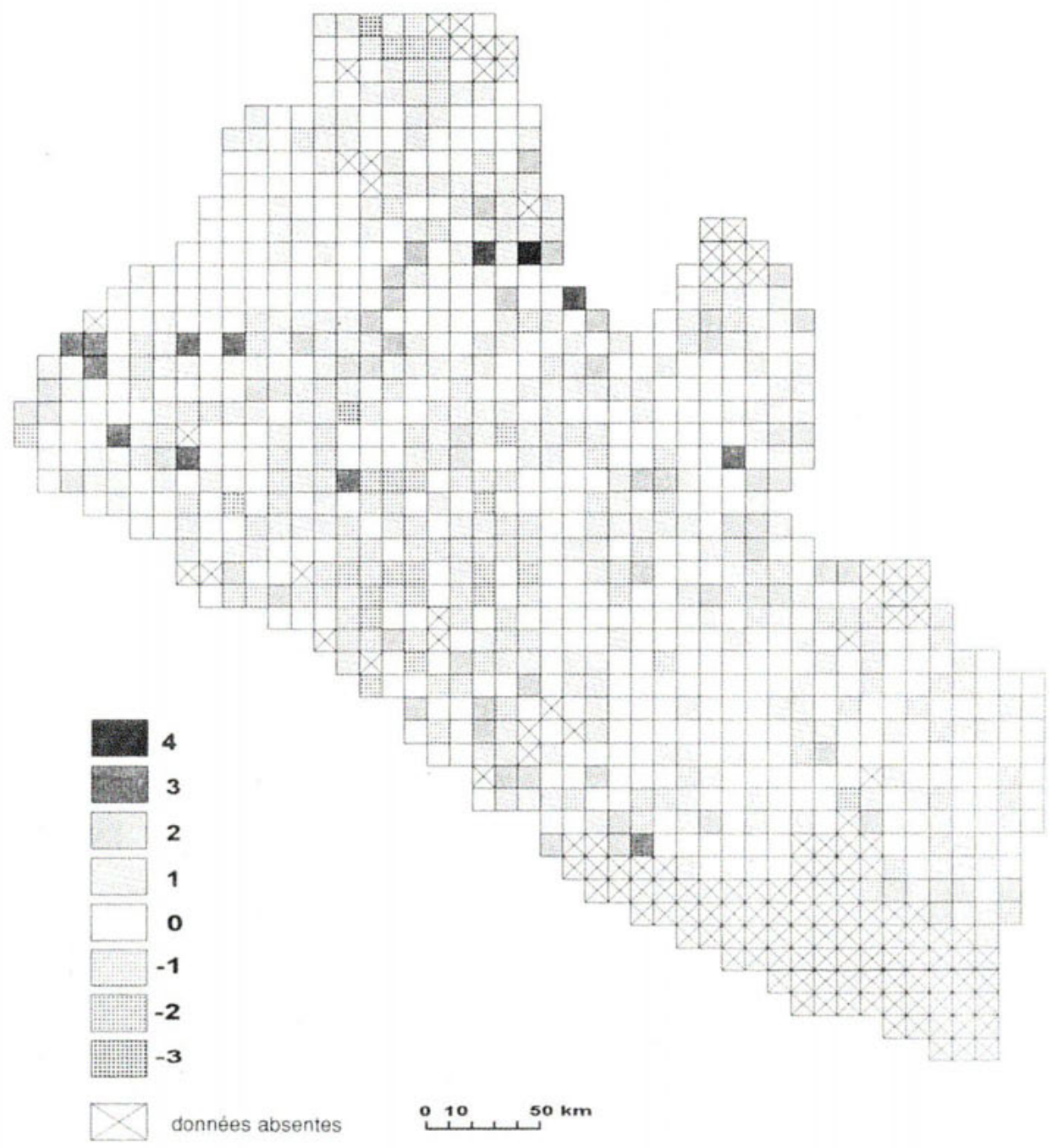

Fig. 7. Différences entre les changements des rangs des densités de population et les changements des rangs des catégories d'utilisation du sol. 


\section{BIBLIOGRAPHIE}

Republic of Liberia. Planning and Development Atlas, Monrovia 1983.

Skotnicki M., 1986, "Densité de population et intensité d'utilisation du sol en Afrique Noire”, Miscellanea Geographica, pp. 279-284. 